\title{
Correspondence
}

\section{Disputed Interpretation of a Pronoun}

Sir,-I make the following comment on Hammerton's letter (Nature, 227, 202; 1970). Tochnical accuracy in grammar may be necessary, but is not sufficient, for the construction of good language. The latter ensures that concepts aro transferred unambiguously and free of distortion by the channel of communication. Chomsky's example", "Learning that John had won the race surprised him", can be defended grammatically for either interpretation of the pronoun, but is not good usage when the "him" refers to John. It is trivial to devise alternative renderings which remove any ambiguity.

Hammerton's report on the survey may indicate merely that the answer invariably given to question (2) was in spite of the ambiguity in the crucial sentence and because of the context. Perhaps the survey should have included the additional question: "Does the penultimate sentence ideally express the meaning intended ?".

It seems a matter for neither surprise nor dispute that the interpretation of a sentence can depend on the context. Yours faithfully,

D. M. Rofssler

Department of Physics,

Research Laboratories,

General Motors Corporation,

Warren, Michigan 48090.

Chomsky, N., Language and Mind (Harcourt, Brace \& World, New York, $1968)$.

SIR,-To further a linguistic argument, M. Hammerton ${ }^{1}$ has constructed a paragraph which is not normal English. The sentence "Learning that John had won the race surprised him" is contorted. The normal sentence in this position in this context would be "Learning that he had won the race surprised John". Hammerton seems to think that the validity of his paragraph has been established by the fact that twenty people said that they understood the passage.

Throughout our lives we are accustomed to hearing or reading sentences which are faultily constructed or in bad English. To facilitate the communication of ideas, and to avoid perpetual pedantry, we have learned the practice of making a best guess at the intentions of the speaker or writer. Absence of comment on grammar is a token of the willingness of the recipient, and is no proof in itself that a passage is in correct English.

Before drawing any more conclusions from his present interview answers, Hammerton might contemplate the exact nature of the questions he asked his interviewees, or the circumstances in which twenty people permitted themselves to accept and discuss without criticism his constructed paragraph. $\mathrm{He}$ could find it enlightening to offer his paragraph to twenty more people and, instead of asking if they understand the passage, make the state ment-whether he believes it himself or not-that it contains some peculiar English and invite them to correct it.

$$
\text { Yours faithfully, }
$$

J AMEs M. LitTle

4 Sheepcote,

Welwyn Garden City,

Hertfordshire.

1 Hammerton, M., Nature, 11 July 1970.

Sir,-I have read the letter by Hammerton with considerable interest and would like to congratulate Bill or John for winning the race. I feel a little sad, however, that umecessary dispute, misery and sourness have arisen as a result of this sporting event. This could have been obviated by more efficient means of communication. It is to be regretted that the results of the race were not made known earlier. Uncertainty of this kind is certain to have an adverse effect on juvenile psychology. We have enough problems on our hands already without manufacturing others. I sav this problem need never have occurred.

The fault lies not with John or with Bill. It is obvious that the race was a very close thing and the loser, whether he be John or Bill, is to be highly commended on a fine performance. The competitive spirit should be fostercd whether in games or in more serious affairs such as, for example, scientific research or the interpretation of a pronoun.

The whole trouble can be laid fairly and squarely at the feet of our teachers of the English language. They have failed in their task, it seems, by not learning their pupils proper grammer. 'This is a deplorable situation.

$$
\begin{aligned}
& \text { Yours faithfully, } \\
& \text { EDward GURI }
\end{aligned}
$$

Michrome Laboratories,

East Sheen,

London SW14.

\section{Scientific Heresy}

SiR,- The theologians of the Renaissance dogmatically refuted Galileo's cosmology, believing it would make nonsense of their theology. For the last twenty years, many eminent scientists, most of whom having grown up under the shadow of Hitler are emotionally involved and therefore, according to criteria put forward by Professor Hudson in Cambridge, unreliable witnesses, have been dogmatically asserting that there are no hereditary differences whatever in the average abilities of human racial groups to carry out mental tasks.

The motive for this dogma seems to be that to admit otherwise would be to pave the way for racist policies. Scientists putting forward contrary views find that even the assurances which they are forced to give that they are not racists are hardly sufficient to protect them from verbal attacks usually reserved for those who deny transubstantiation.

This form of dogmatic theology is not merely bad science: it is even worse politics. For just as Galileo warned his theologians not to prepare for their own destruction should his scientific theories bo proved right, so the liberal scientists should have seen that their attitude would, by implication, admit the rightness of racist policies should it be shown that ethnic groups do differ in mental capacities. They have put themselves in the position of the church over both Galileo and Darwin; could this be why they are so mad with Professor Jensen?

They ought to have remembered that you "can't get an ought from an is", a truth that scientists, ever since attempts to derive ethies from evolution, have found hard to accept. The sensible position for a liberal scientist, and the only truly non-racist one, is that as a matter of "is" there may or may not be innate differences in the average ability of races for particular mental tasks, but that as a matter of "ought" this matters not a rap, and that people must be treated on their own merits as individuals, and not on the real or imagined qualities of any group, racial or otherwise, to which they belong.

Yours faithfully, J. R. G. 'TuRNER

University of York,

Heslington, York, YO1 5DD. 